\title{
Caffeinism Associated With Greater Use of Other Psychotropic Agents
}

\author{
John F. Greden, Andrew Procter, and Bruce Victor
}

$\mathbf{C}$ AFFEINISM, a diagnosis recently included in the third edition of the American Psychiatric Association's Diagnostic and Statistical Manual of Mental Disorders (DSM-III), ${ }^{1}$ is characterized by a constellation of affective, sleep, and psychophysiological manifestations. ${ }^{2}$ Because symptoms of caffeinism might be confounded or masked by simultaneous ingestion of other drugs, it is pertinent to ask whether high consumers of caffeine differ from low or moderate consumers in their use of other psychoactive agents. Few data are currently available to answer this question.

Historically, 18th-century physicians suggested that tea and coffee consumption promoted later use of alcohol, opium, and other stimulants. ${ }^{3}$ Such claims were never proven. In contrast, increased cigarette smoking has been conclusively associated with high caffeine consumption. ${ }^{4-7}$ Although Greden et al. ${ }^{7}$ noted that a greater proportion of high caffeine consumers reported use of minor tranquilizers when compared with low or moderate caffeine users, few or no studies have described patterns of use for hypnotics, neuroleptics, antidepressants, or lithium among subgroups of caffeine users.

The importance of documenting possible interactions between use of caffeine and use of other drugs increased with several recent discoveries. First, caffeine was shown to interact in vitro with a number of neuroleptics to form flaky precipitates and thus possibly impair the efficacy of these agents. ${ }^{8.9}$ Second, caffeine clinically antagonizes barbiturates ${ }^{10}$ and monoamine oxidase inhibitors (MAOI). ${ }^{11}$ Third, caffeine and caffeine withdrawal have been noted to alter adrenergic and serotonergic transmission, and thus may interfere with expected results from common psychiatric medications. ${ }^{2.12}$ Finally, following the exciting discovery that the brain contained specific receptors for benzodiazepines, it was noted that caffeine was a competitive inhibitor of diazepam binding to these brain receptors. ${ }^{13,14}$ Conceivably, competitive interference

From the University of Michigan Medical Center, Ann Arbor, Mich., and Langley Porter Hospital, San Francisco, Calif.

John F. Greden, M.D.: Professor of Psychiatry, Director, Clinical Studies Unit, Scientific Associate, Mental Health Research Institute, Department of Psychiatry, University of Michigan Medical Center, Ann Arbor, Mich.; Andrew Procter: Medical Student, Guy's Hospital Medical School, London, England; Bruce Victor, M.D., Department of Psychiatry, Langley Porter Hospital, San Francisco, Calif.

Supported in part by the Mental Health Research Institute, Department of Psychiatry, University of Michigan Medical Center, Ann Arbor, Mich.

Address reprint requests to John F. Greden, M.D., Department of Psychiatry, University of Michigan Medical Center, Ann Arbor, Mich. 48109.

(C) 1981 by Grune \& Stratton, Inc. 0010-440X/81/2206-0005\$01.0010 
with endogenous benzodiazepine ligands might even explain caffeine's stimulant, anxiety-like actions.

To assess whether use of other psychoactive agents differed among caffeine using subgroups, we studied 205 hospitalized patients and compared three subgroups of caffeine users. We observed that: (1) low, moderate and high caffeine-consuming subgroups differed in their use of other psychoactive substances, specifically tobacco, minor tranquilizers, and sedative-hypnotics; (2) similar patterns of associated psychotropic drug use were found among psychiatric and nonpsychiatric patients, although amounts were greater in psychiatric patients; and (3) caffeine-using subgroups did not differ in their use of neuroleptics, antidepressants, lithium, or stimulants. This article describes these results in detail.

\section{MATERIALS AND METHODS}

\section{Data Collection}

A 220-item questionnaire was administered to 205 hospitalized patients at the University of Michigan Medical Center. As described more extensively in earlier publications, ${ }^{7,15}$ the questionnaire consisted of an informed consent form, demographic information, and 190 keypunchable items. The form determined total caffeine intake by summing caffeine ingestion from all common sources, including tea, coffee, cola drinks, and 25 caffeine-containing medications. We assessed other psychoative drug use by inquiring about frequency and quantity of each subject's intake of tobacco, minor tranquilizers (benzodiazepines or meprobamate), neuroleptics, antidepressants, sedative-hypnotics, lithium, and stimulants. To enhance response accuracy, common pharmaceutical brand names were included in the questionnaire (e.g., Valium, Thorazine, Secanol). We emphasize that we assessed use of caffeine and other drugs prior to hospitalization. The questionnaire had been previously pilot tested, validated by interview, and employed in other studies. ${ }^{715,16}$

\section{Subjects}

Respondents included 81 hospitalized psychiatry patients, and 124 hospitalized nonpsychiatry patients. The latter were operationally defined as individuals who had never received treatment by a psychiatrist. They conceivably could have received psychotropic agents from nonpsychiatric physicians. Demographic characteristics of both subgroups are illustrated in Table 1. The two subgroups differed significantly in sexual distribution and marital status, but not in age, race, religion or educational level $(p>0.05)$. Neither sex nor marital status have been shown to significantly modify caffeine intake. ${ }^{7}$ Thus, we concluded that the two subgroups could be compared with each other. Furthermore, in this study we primarily sought to evaluate drug use among different caffeine-consuming subgroups and studied nonpsychiatric patients mainly because many of the drugs we were assessing are commonly prescribed in psychiatric settings. If greater use of other psychoactive drugs were truly linked to caffeine use, such a pattern would need to be documented among nonpsychiatric as well as psychiatric patients.

\section{DATA ANALYSIS}

For purposes of comparing caffeine-using subgroups, ${ }^{7}$ we divided subjects into three categories depending upon their total caffeine intake. These included: (1) low consumers (0-249 mg per day); (2) moderate consumers (250-749 mg per day); and (3) high consumers ( $750 \mathrm{mg}$ or more per day). Use of other psychotropic agents was then compared among these three subgroups. Chi square analysis was utilized, accepting $p<0.05$ as indicating significance. 
Table 1. Demographic Characteristics of Psychiatric and Nonpsychiatric Groups, in Percentages

\begin{tabular}{|c|c|c|}
\hline & $\begin{array}{l}\text { Psychiatric } \\
(n=81)\end{array}$ & $\begin{array}{c}\text { Nonpsychiatric } \\
\quad(n=124)\end{array}$ \\
\hline \multicolumn{3}{|l|}{ Age ${ }^{\dagger}$} \\
\hline$<25$ years & 31 & 20 \\
\hline $26-40$ years & 34 & 36 \\
\hline 41 and above & 35 & 44 \\
\hline \multicolumn{3}{|l|}{ Sex* } \\
\hline Female & 30 & 69 \\
\hline Male & 70 & 31 \\
\hline \multicolumn{3}{|l|}{ Race ${ }^{\dagger}$} \\
\hline Non-White & 8 & 8 \\
\hline White & 92 & 92 \\
\hline \multicolumn{3}{|l|}{ Marital Status* } \\
\hline Nonmarried & 58 & 25 \\
\hline Married & 42 & 75 \\
\hline \multicolumn{3}{|l|}{ Religiont } \\
\hline Catholic & 32 & 33 \\
\hline Protestant & 52 & 60 \\
\hline Other & 16 & 17 \\
\hline \multicolumn{3}{|l|}{ Educationt } \\
\hline$<$ High School & 36 & 31 \\
\hline High School & 28 & 31 \\
\hline$>$ High School & 36 & 38 \\
\hline
\end{tabular}

* Chi square, $p<0.001$

$\dagger$ Chi square, nonsignificant at 0.05 level.

\section{RESULTS}

\section{Total Caffeine Use}

When the total sample of 205 subjects was considered, $39.5 \%$ were low caffeine consumers, $42.5 \%$ were moderate consumers, and $18.0 \%$ ingested more than $750 \mathrm{mg}$ caffeine per day, qualifying as high consumers. The psychiatric and nonpsychiatric subjects did not differ significantly in their caffeine use, although an observable trend was that $16 \%$ of the nonpsychiatric patients were high consumers, compared with $23 \%$ of the psychiatric patients.

\section{Drug Use Among Caffeine-Consuming Subgroups in the Total Sample}

Figure 1 illustrates reported use of other psychotropic drugs within the past month among the three caffeine-consuming subgroups. In the total sample of 205 subjects, as caffeine use increased from low to moderate to high we noted a corresponding increase in the percentage using cigarettes. Specifically, 69\% of high caffeine consumers smoked tobacco, compared to only $31 \%$ of low caffeine users (chi square $=p<0.001$ ). A greater percentage of high caffeine users also reported use of minor tranquilizers (benzodiazepines or meprobamate) within the past month, (chi square $=p<0.01$ ). In contrast to these statistically-significant differences, use of stimulants, sedative hypnotics, major tranquilizers, antidepressants, and lithium failed to differ significantly among the three subgroups. 


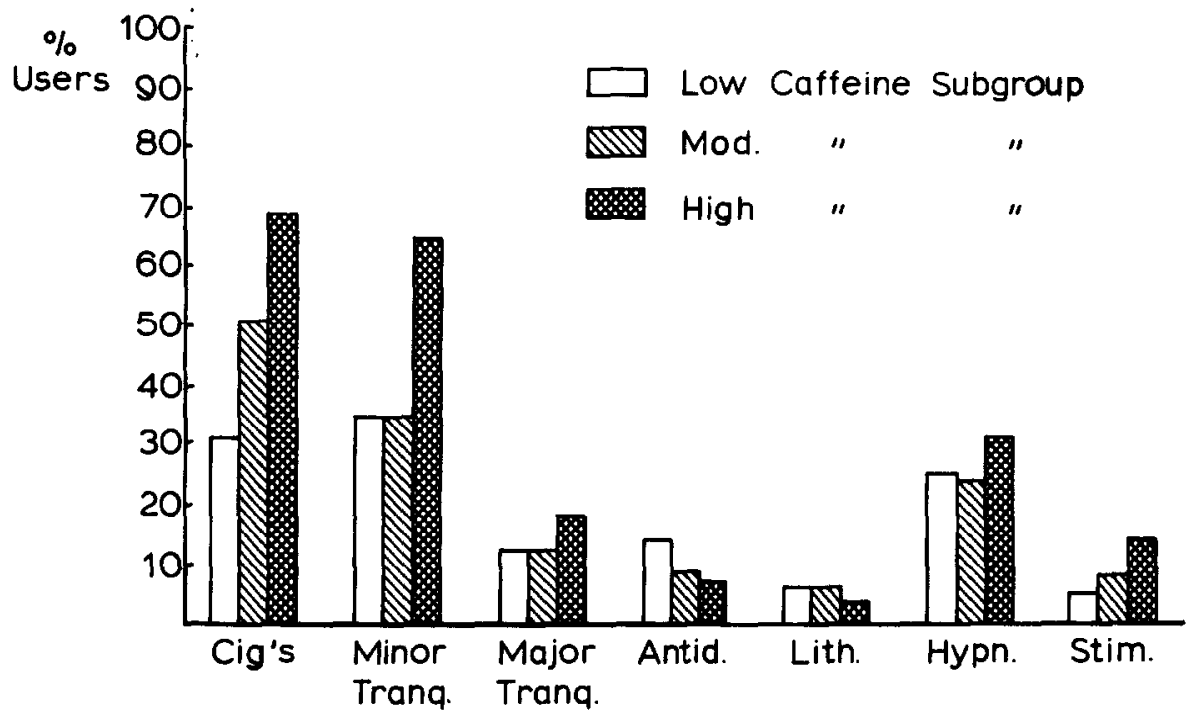

Fig. 1. Reported use within past month of cigarettes, minor tranquilizers, major tranquilizers (neuroleptics), antidepressants, lithium, sedative-hypnotics, and stimulants among the three caffeine-consuming subgroups.

\section{DRUG USE AMONG CAFFEINE-CONSUMING SUBGROUPS: PSYCHIATRIC VS. NONPSYCHIATRIC PATIENTS}

To address the comparison between psychiatric and nonpsychiatric subjects, we focused upon the three drugs whose use differed most significantly in association with caffeine use, i.e., cigarettes, minor tranquilizers, and sedativehypnotics. The use of these three agents was greater in all caffeine-using subgroups among psychiatric patients when compared with nonpsychiatric subjects (Fig. 2). Stated differently, low caffeine-consuming psychiatric patients had more associated drug use than low caffeine-consuming nonpsychiatric patients, and similarly for moderate and high caffeine users. In both psychiatric and nonpsychiatric subgroups, however, the highest caffeine users generally also had the highest associated use of other psychoactive drugs, indicating this was not simply related to psychiatric patient status.

Eighty-two percent of psychiatric patients who ingested more than $750 \mathrm{mg}$ caffeine per day also reported smoking, seventy-one percent used minor tranquilizers, and $53 \%$ reported recent use of sedative-hypnotics. The magnitude of these figures is noteworthy.

When we further analyzed frequency of drug use, specifically measuring "occasional" use (operationally defined in the questionnaire as once a week or less) or "regular" use (operationally defined as twice a week or more frequently), patterns identical to monthly use were found. In comparison to nonpsychiatric patients, more high caffeine-consuming psychiatric patients reported occasional and regular use of sedative-hypnotics, minor tranquilizers, and cigarettes. Forty-one percent of psychiatric high caffeine consumers reported regular use of minor tranquilizers and $24 \%$ regular use of sedativehypnotics, compared to $15 \%$ and $5 \%$ of nonpsychiatric high caffeine users, 


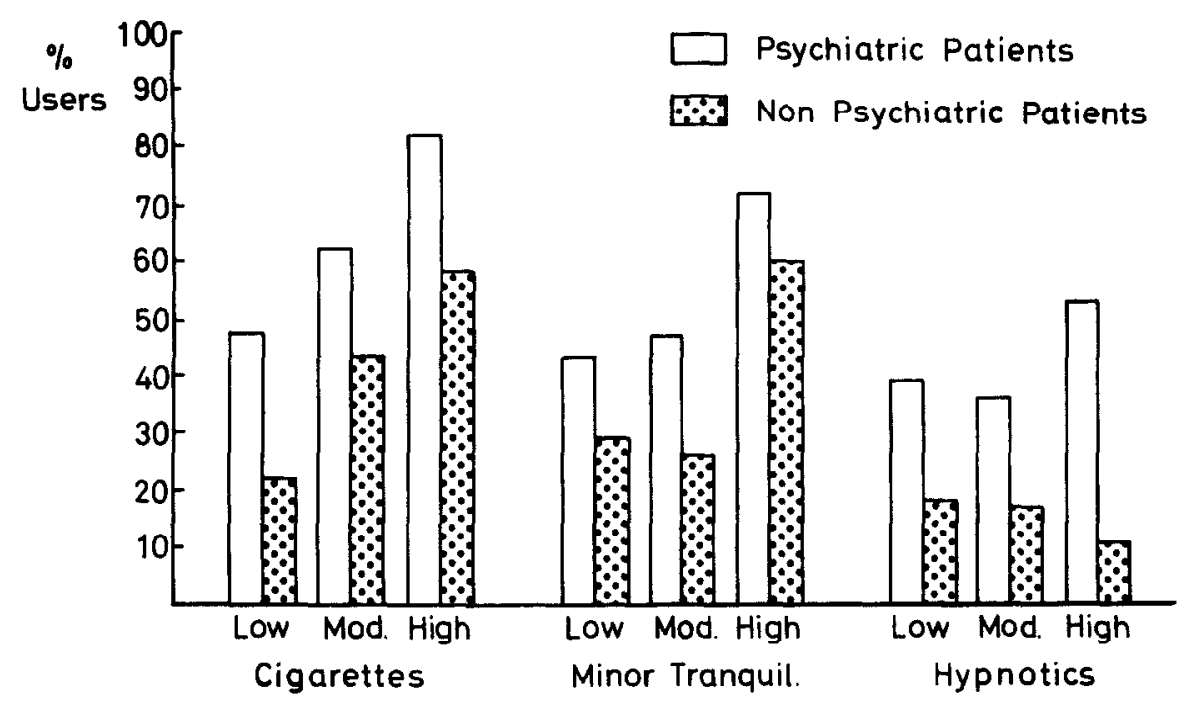

Fig. 2. Comparison between psychiatric and nonpsychietric patients in reported use of cigarettes, minor tranquilizers, and sedative-hypnotics within the past month.

respectively. To reiterate, however, heaviest caffeine consumers-whether psychiatric or nonpsychiatric-had the highest use.

\section{DISCUSSION}

These data document for the first time that among high caffeine consumers, there is significantly greater use of selected other psychoactive drugs, whether individuals are psychiatric or nonpsychiatric patients. Most high caffeine consumers smoke extensively. The majority report recent use of benzodiazepines or meprobamate. Approximately half report recent use of sedative hypnotics. We suggest that these polydrug patterns have potential clinical implications.

Tobacco use, for example, has been shown to complicate prescribed psychiatric treatments, partially because nicotine activates the hepatic enzyme system and lowers plasma levels of neuroleptics and tricyclic antidepressants. ${ }^{17}$ High caffeine use may similarly interfere with the desired clinical effects of psychiatric medications by counteracting their desired effects ${ }^{2}$ or by formation of flaky precipitates and decreased absorption, as described previously. ${ }^{8.9}$ Since only combined caffeine and tobacco use has been shown to alter lipoprotein levels, ${ }^{18}$ it is also conceivable that combined use of these two drugs could produce psychiatric consequences not characteristic of either drug alone. Assessment of this possibility is indicated.

The finding that $65 \%$ of high caffeine users in the total sample reported use of minor tranquilizers within the past month has definite epidemiological significance. Several factors may contribute to this combined use. Heavy users, for example, might ingest minor tranquilizers in an attempt to counteract the toxic manifestations of high caffeine consumption. As previously reported, ${ }^{7,16}$ the clinical picture of a person with caffeinism may be so similar to patients with an anxiety state that there may be diagnostic confusion. Physicians might then prescribe benzodiazepines rather than recommend elimination of caffeine. 
The neurobiological mechanism underlying this pattern is probably related to the fact that caffeine and endogenous benzodiazepine ligands compete with each other for the same brain receptor sites. ${ }^{13,14}$ Thus, it would be predictable that as caffeine use increased, receptor competition would also increase, interfering with the "tranquilizing" effects of endogenous benzodiazepine ligands and producing CNS excitation. The highest caffeine users might then seek to restore the balance by greater use of "exogenous" benzodiazepines, as observed in our study sample. This documented association raises important clinical concerns. If benzodiazepines are effective in minimizing symptoms of caffeinism, the manifestations of such a syndrome may be chronically masked by these drugs. The treatment of choice, in fact, ought to be reduction of caffeine intake, rather than adding an anxiolytic agent. Inversely, in cases when anxiety is due to other causes and benzodiazepines are appropriately prescribed, it seems likely that their efficacy might be reduced by excessive caffeine use, perhaps even when consumed in small quantitics. This emphasizes the importance of asking patients about caffeine use. Certainly, in evaluating the claimed over-utilization of benzodiazepines, associated caffeine use should always be considered a confounding factor. Such consideration has been rare.

Our finding that $24 \%$ of high caffeine consuming psychiatric patients reported regular use (twice per week or more) of sedative hypnotics is noteworthy. Analogous to the reported use of benzodiazepines, an antagonistic interaction is suggested. These findings support earlier observations by Forrest et al. ${ }^{10}$ that caffeine use at bedtime counteracts sedative-hypnotics. Long-term use of sedative-hypnotics is clinically questionable in most patients, but in patients with caffeinism it would seem especially dubious.

In contrast to differences in use of tobacco, minor tranquilizers or sedative hypnotics, caffeine-consuming subgroups did not differ in their reported use of major tranquilizers, antidepressants, or lithium. This suggests that the use of these latter agents primarily reflects prescribing patterns among physicians rather than drug-seeking behaviors among caffeine users. Another possibility is that caffeinism does not as frequently mimic the conditions for which neuroleptics, antidepressants, and lithium usually are prescribed, in contrast to anxiety and sleep disturbances which commonly lead to prescription of minor tranquilizers or sedative-hypnotics.

Although highest caffeine consumers reported greatest use of other psychotropic agents, whether they were psychiatric or nonpsychiatric patients, such intake was clearly more among those receiving treatment for psychiatric problems. Cause and effect relationships cannot be inferred from our study design. We wonder whether this observed increase in use of other psychoactive agents among caffeine-consuming psychiatric patients is related to more frequent prescriptions of common treatments for spontaneously-occurring psychiatric problems, to relief-seeking from previously-occurring caffeinism, or perhaps even casually contributing to their current psychiatric status. Only longitudinal assessments will adequately answer these important questions.

Hundreds of millions of persons experience the pharmacological effects of caffeine each day and a number of psychiatric implications have been iden- 
tified from such use. The drug induces a distinct clinical syndrome, i.e., caffeinism. ${ }^{7.16}$ It can modify the clinical manifestations of spontaneously-occurring affective disorders. ${ }^{19}$ It has been reported to precipitate or exacerbate psychoses. ${ }^{7,20,21}$ Intravenous use of the drug helps reverse Parkinsonian symptoms associated with neuroleptic use. ${ }^{22}$ Caffeine withdrawal syndromes are frequent. ${ }^{15,23}$ In addition to these previously-reported psychiatric effects, results from this study suggest that high caffeine use is associated with greater use of various psychotropic agents. Future evaluations of these polypharmacy patterns are required, because with the high prevalence of such combined use, the clinical implications are potentially enormous.

\section{REFERENCES}

1. Diagnostic and Statistical Manual of Mental Disorders (ed. 3). Washington, D.C., American Psychiatric Association, 1980

2. Greden JF: Caffeine and tobacco dependence, in Kaplan HI, Freedman AM, Sadock BJ (eds): Comprehensive Textbook of Psychiatry (ed. 3). Baltimore, Williams and Wilkins, 1980, pp 1645-1652

3. Greden JF: The tea controversy in Colonial America. J Am Med Assoc 236:63-66, 1976

4. Friedman GD, Siegelaub AB, Seltzer CC: Cigarettes, alcohol, coffee, and peptic ulcer. N Engl J Med 290:469-473, 1974

5. Gilbert RM: Caffeine as a drug of abuse, in Gibbin $R G$, Israel $Y$, Kalant $H$, et al (eds): Research Advances in Alcohol and Drug Problems. New York, John Wiley and Sons, 1976, p 49

6. Dawber TR, Kannel WB, Gordon T: Coffee and cardiovascular disease-observations from the Framingham study. N Engl J Med 291:871-874, 1974

7. Greden JF, Fontaine P, Lubetsky M, et al: Anxiety and depression associated with caffeinism among psychiatric inpatients. Am J Psychiatry 135:963-966, 1978

8. Kulhanek F, Linde $O K$, Meisenbert G: Precipitation of antipsychotic drugs in interaction with coffee or tea. Lancet 2:1130, 1979

9. Hirsch SR: Letter to the editor. Lancet 2:1130-1131, 1979

10. Forrest WH, Bellville VW, Brown BW: The interaction of caffeine with pentobarbitol as a nightime hypnotic. Anesthesiology 36:37-41, 1972

11. Berkowitz BA, Spector S, Pool W: The interaction of caffeine, theophylline and theobromine with monoamine oxidose inhibitors. Eur J Pharmacol 16:315-321, 1971

12. Gibson CJ: Caffeine withdrawal elevates urinary MHPG excretion. N Engl J Med 304:363, 1981

13. Paul SM, Marangos PJ, Goodwin FK, et al: Brain-specific benzodiazepine receptors and putative endogenous benzodiazepine-like compounds. Biol Psychiatry 15:407-428, 1980

14. Tallman JF, Paul SM, Skolnick P, Receptors for the age of anxiety: pharmacology of the benzodiazepines. Science 207:274-276. 1980

15. Greden JF, Victor BS, Fontaine $P$, et al: Caffeine withdrawal headache: A clinical profile. Psychosomatics 21:411-418, 1980

16. Greden JF: Anxiety or caffeinism: A diagnostic dilemma. Am $\mathbf{J}$ Psychiatry 131:1089-1094, 1974

17. Beckett AH, Triggs, EJ: Enzyme induction in man caused by smoking. Nature 216:587-589, 1967

18. Heyden S, Tyroler HA, Heiss G, et al: The combined effects of smoking and coffee drinking on LDL and cholesterol. Circulation 60:22-25, 1979

19. Neil JF, Himmelhoch JM, Mallinger, AG, et al: Caffeinism complicating hypersomnic depressive episodes. Compr Psychiatry 19:377-387, 1978

20. Mikkelsen EJ: Caffeine and schizophrenia. J Clin Psychiatry 39:732-735, 1978

21. Winstead PK: Coffee consumption among psychiatric inpatients. Am J Psychiatry 133:1447-1450, 1976

22. Freyhan FA: Therapeutic implications of differential effects of new phenothiazine compounds. Am J Psychiatry 115:577-585, 1959

23. White BC, Lincoln CA, Pearce NW, et al: Anxiety and muscle tension as consequences of caffeine withdrawal. Science 209: 1547-1548, 1980 